\title{
Appropriating Virtual Learning Environments: A Study of Teacher Tactics
}

Jan Derboven $^{\mathrm{a}, \mathrm{b}}$, David Geerts ${ }^{\mathrm{a}}$, Dirk De Grooff ${ }^{\mathrm{a}}$

firstname.lastname@kuleuven.be

${ }^{a}$ Meaningful Interactions Lab, KU Leuven-iMinds

Parkstraat 45 bus 3605

3000 Leuven, Belgium

${ }^{\mathrm{b}}$ Corresponding author 


\section{Appropriating Virtual Learning Environments: A Study of Teacher Tactics}

\section{Abstract}

In research on Virtual Learning Environments (VLEs), it has been shown that teachers often do not explore VLEs to their full potential and only adopt a limited set of the available tools. In this article, we approach teachers' design of VLE learning activities as end user development. We describe a study of Toledo, a virtual learning environment used across several higher education institutions in Belgium. Using a combination of a semiotic, multimodal analysis and an in-depth user study with 24 respondents, we provide a detailed account of how teachers appropriate the learning environment to suit their needs. Combining the insights from the semiotic investigation and the user research, we analyze how user appropriations can be explained as practices emerging from both how the platform communicates, and contextual factors. The study showed that some teachers design very specific learning activities using the VLE - not by using the dedicated VLE tool, but by reinterpreting more generic tools. These appropriation tactics concentrate platform use in a limited number of tools, even when teachers do use more complex learning activities. These results have implications for the design of VLEs: rather than offering a wide range of tools targeted at specific learning activities, VLEs could concentrate on providing basic communication tools that are open for appropriation.

\section{Keywords}

Appropriation, Virtual Learning Environment, Semiotics, Multimodality.

\section{Introduction}

Despite the fact that social networking technologies have been on the uprise in computersupported collaborative learning (CSCL) for several years now (Hemmi et al., 2009; Hamid et al., 2014), more 'classical' virtual learning environments (VLEs) such as Blackboard are still used most often in practice (Prieto et al., 2013). However, these VLEs have often been criticized over the past decade. Research has pointed out that it is difficult to encourage authentic learning or collaboration using VLEs (Conole \& Dyke, 2004), that teachers often do not explore VLEs to their full potential and only adopt a limited set of functionality (Hemmi et al., 2009; Veletsianos et al., 2013), and that even prolonged use does not lead teachers to using such platforms in more interactive ways (Christie et al., 2011).

Existing research has already focused on various aspects that influence teacher decisions in adopting VLEs, including institutional policies (Bennett et al., 2011) and pedagogical beliefs (Berggren et al., 2005). Despite this large amount of both quantitative and qualitative research on VLEs, several authors call for more research on teacher's practices, for instance on which factors influence teachers' design of learning activities (Bennett et al., 2015), on why specific technologies 'work' in the classroom or not (Balaam, 2013), and on user needs and the affordances of various tools (Kali et al., 2011). In this paper, we focus on how teachers make VLEs work for them. Specifically, we focus on the domain of technology appropriation: a line of research that focuses on how users adopt and adapt technologies, and fit them into their daily practice (Veletsianos et al., 2013; Hamid et al., 2014; Wen et al., 
2014; Wen et al., 2015). Considering VLEs as flexible environments that allow for extensive tailoring (Won et al., 2006), we investigate how teachers, as end-users of VLEs, cope with the tailorability of such platforms. In this way, we contribute a new perspective on the uptake of VLEs by teachers, and how and why some teachers adopt only a limited set of functionalities.

While research in educational technology has focused most often on either the characteristics of technology or on user behaviour, we combine the two perspectives. We combine an indepth analysis of the structure of a VLE, and the teachers' appropriations of it. On the one hand, we focus on how the technology, through its design and affordances, guides its users. To this end, we use an analytic method based on semiotics, the study of signs. On the other hand, we investigate how teachers appropriate technology, developing specific practices to meet their own needs, sometimes resisting the guidance offered through the design of the technology. These specific teacher appropriations are investigated through ethnographic HCI (human-computer interaction) methods (see, e.g. Blomberg and Burrell, 2012). Using a combination of these HCI methods, we offer a new, detailed insight into how specific elements in the design of VLEs play a role in the teachers' appropriation. In an interpretative, qualitative study with 24 university and university college teachers, we explore how teachers cope with the constraints and structures related to the VLE, how they find solutions to make the technology work for them, and how they communicate these solutions. By analyzing the shifts in meaning, and clarifying appropriation mechanisms, we identify design recommendations for future learning environments. This will allow us to expose the consequences of VLE design choices in situated contexts of use (Salovaara et al., 2011).

\section{Background}

\subsection{Teacher Roles in the Design of Virtual Learning Environments}

It has been identified by several authors that opinions and expectations regarding educational technology and virtual learning environments have differed widely. While some researchers have considered VLEs to be unable to support effective learning processes (Pereira et al., 2013), for others, VLEs have been the subject of high hopes since the 1990s (see, e.g., Garrote \& Pettersson, 2011, Hamilton \& Feenberg, 2012). These high hopes were based on the expectation that effective learning environments would improve the learning experience, and facilitate more flexibility in education (e.g., Garrote \& Pettersson, 2011). To this end, numerous companies and educational institutions around the world invested in virtual learning environments, often offered by commercial software developers (Garrote \& Pettersson, 2011; Hamilton \& Feenberg, 2012). However, these environments, to some extent, failed to live up to the expectations: research has pointed out that teachers do not explore VLEs to their full potential and only adopt a limited set of functionality (Hemmi et al., 2009; Veletsianos et al., 2013).

Pereira et al. (2013) identified 28 critical aspects of social technology (e.g., adaptability, affording collaboration, and usability), which are also relevant for the design of VLEs. Pereira et al. consider these aspects as values embedded in such platforms. Platforms that emphasize a different set of values can therefore be more, or less suitable for specific activities. For instance, Hamilton and Feenberg (2012) have observed that modern commercially available VLEs such as Blackboard tend to stress automation of learningrelated activities through their design, rather than social interaction. They argue that this type of VLEs stress task automation, downplaying the communicative role of teachers in the teaching process, while alternatives like the open source platform Moodle do "stress the interrelation between teachers and students as a communicative and a collaborative one" 
(Hamilton \& Feenberg, 2012). In their view, Moodle also offers tools for task automation, but it focuses on the the relational aspect of the technology and the communicative role of the teacher. In Pereira et al.'s (2013) terminology, Moodle stresses the value of collaboration, in contrast to platforms such as Blackboard. In this article, we set out to identify the values embedded in the design of a specific VLE, and investigate how teachers cope with these design choices in their everyday use.

\subsection{Teachers' Appropriation and End User Development}

The design of technology is one important aspect that influences users' actions, but users can also appropriate the technology for their own purposes (Medina \& Suthers, 2012): "technology is a composite of the technical artifact and the practical actions of its users" (Overdijk et al., 2014). The CSCL community has recognized that teachers have a double role as a designer and as a user of VLEs - (e.g. Hamid et al., 2014; Wen et al., 2015). This can be seen as a type of end-user development: teachers actively tailor the environment as they customize VLE tools, and integrate them into their course designs (Mørch, 1997). In the context of education, this tailoring has been echoed in the conceptualization of teachers as bricoleurs (Hatton, 1988; Hutchinson, 2011; Sharples et al., 2014). Sharples et al. define bricolage, with regard to educational technology, as the "creative exploration of the practices and technologies needed to achieve an educational goal" $(2014$, p. 35$)$ : teachers explore the possibilities of technologies and tools to compile and design their learning activities. Tailoring and personalizing VLEs, then, is part of this exploration. Hutchinson (2011) calls for a more collaborative 'co-learning' between teachers, allowing them to share their experiences. In this respect, the collaborative tailoring scenarios described by Pipek and Kahler (2006) can be useful to extend the current understanding of bricolage in education.

Research into teachers' use and appropriation of educational technology has focused on various aspects, including pedagogy (e.g., Berggren et al., 2005; Bennett et al., 2015), institutional policies (Bennett et al., 2011) and how the interaction between teacher and students shapes the use of educational tools (Wen et al., 2015). This research has clarified how teachers set educational goals (what should an activity achieve for students? - Bennett et al., 2015), how they align educational technology with learning theory, and how they encourage students to use that technology (Hamid et al., 2014). When researching teachers' exploration of technologies, however, it is important to be attentive to both design of the educational technology, and to the users' interpretation of that design. To this end, Suthers (2005) and Holmberg (2014) argue for an approach that stresses interpretation and meaningmaking, as using technology has become a matter of " interpreting' the affordances of educational technologies and how these can be used in educational designs" (Holmberg 2014: p. 297). In this article, we focus specifically on the interaction between the design of the technology and the situated use and appropriation of VLEs, using a method based on semiotics, the study of signs.

\subsection{Semiotics in Human Computer Interaction and Science and Technology Studies}

Semiotics, a theory originating in linguistics and formal logic, is often defined as the study of signs, concentrating on meaning-making and representation in texts and other media (Chandler, 2007). In the field of HCI, semiotic frameworks have been developed to analyze, guide, and evaluate design. For instance, Andersen developed a design method based on a semiotic analysis of how technology-based signs mediate people's interaction with that technology (Andersen, 1990). De Souza (2005) developed the semiotic engineering theory, characterizing technology applications as 'metacommunication artifacts', in which user interfaces are seen as "one- shot, higher-order messages sent from designers to users" (Prates et al., 2000, p. 31). In this view, the user interface speaks for the designers: the interface 
contains all the meanings that interface designers have embedded in them. Semiotic approaches to specific areas of HCI have also been developed. For instance, O'Neill (2008) developed a semiotic approach to embodied interaction, and Kjeldskov and Paay (2010) used a semiotic approach to study mobile HCI in context. In this literature, semiotics has been used to inform the design process (e.g., Liu, 2000), to guide designers in communicating their intentions clearly, or to evaluate communicative clarity (e.g., De Souza, 2005).

While the semiotic HCI research outlined above acknowledges that in design, meanings can never be completely fixed, and that there is always room for creative interpretation, the social consequences of this flexibility are analyzed in more detail in Science and Technology Studies (STS; see, e.g. Woolgar, 1991). Based on the metaphor of the user as a 'reader' of technological 'texts' that are open to interpretation, the 'semiotic approach' in STS (Oudshoorn and Pinch, 2003) stresses meaning-making in appropriation processes. However, this 'semiotic approach' has focused primarily on social processes in user communities, and less on the design of technology as such.

The multimodal social semiotic approach that we developed to research appropriation processes combines the attention to the design of the technology with the attention to situated use in appropriation. Instead of a focus on the designer's communication often found in semiotic HCI methods, multimodal social semiotics allows for a stronger emphasis on the interpretive agency of users. While multimodal social semiotics has been used to analyze both digital technologies (e.g., Jewitt, 2013) and educational practices (e.g., Jewitt, 2006; Bezemer and Kress, 2008; Kress and Selander, 2012) the uptake of multimodality as an analytic framework in HCI, however, has been limited so far (Xambò et al., 2014; Price and Jewitt, 2013).

\section{Appropriation Tactics in VLEs: a Multimodal Semiotic Approach}

\subsection{Design Strategies and User Tactics}

In order to stress both technology design and the interpretive agency of users in appropriation, we frame the relationship between the structures in technology design and the teachers' appropriation practices, as a relation between design strategies and user tactics. This is a distinction based on De Certeau (1984) and Dourish (2006). While the terminology originates in de Certeau's analysis of mass culture, Dourish (2006) has applied it to interaction with technology. "Strategic practices are the practices of design, whereas tactical practices are the practices of use" (2006: 302). Designers create interactive applications with very specific goals in mind: they use specific design strategies to realize their intentions, suggesting or even imposing specific interactions on the users. Using semiotic terminology, technology shapes users' interactions by creating an ideal 'model user' through its design strategies (based on Eco's model reader (Eco, 1979 - see also Derboven et al., 2013, 2016). In this way, a technological artefact has a specific use inscribed in it. Users, however, are not necessarily model users: they can interpret the technology in alternative ways. User tactics, then, are the ways in which users actively impose new meanings, and appropriate the technology based on its characteristics, on personal characteristics (prior knowledge and experiences), and social rules and norms.

We focus on the tension between these two, potentially competing forces. While the scope of manoeuvrability can be limited for users due to design strategies, users can still use the designs in creative ways (Gardiner, 2000) by developing user tactics. To operationalize this distinction between strategies and tactics, however, we need a method for analyzing 
strategies and tactics in more detail. We find a useful starting point in semiotics, specifically in multimodal social semiotics.

\subsection{Multimodal Social Semiotics}

Multimodal social semiotics, also called 'multimodality', builds on social semiotics, an approach originating in systemic functional linguistics (Halliday, 1978), and developed further into an approach to analyze "semiotic systems in social practice" (Hodge and Kress, 1988: 1). As a semiotic approach, multimodality concentrates on how communication is structured, presented and interpreted in social practice, with a focus on agency and social context. This focus has lead to a more social account of signs (Jewitt et al., 2016). In structuralist semiotics (e.g., De Saussure), there is a clear distinction between sign systems as abstract systems (langue) and the use of these systems by people (parole). In contrast, multimodal social semiotics considers sign systems to be shaped "through social usage" (Jewitt et al., 2016, p. 59). This focus makes multimodality a suitable approach to investigate people's reinterpretations and appropriations of technology: it considers that "social structures and processes, messages and meanings [are] the proper standpoint from which to attempt the analysis of meaning systems" (Hodge \& Kress, 1988: vii).

\subsubsection{Semiotic Resources and Modes}

In multimodality, the term 'semiotic resource' is used to refer to various means for making meaning. Van Leeuwen defines the term as follows: "Semiotic resources are the actions, materials and artifacts we use for communicative purposes [...], together with the ways in which these resources can be organized." (van Leeuwen 2005: 285). This definition combines two important aspects we will elaborate on below: first, the actions, materials, and artifacts themselves, and second, the way they are used and organized by people.

In multimodality, actions, materials and artifacts are said to communicate through 'modes'. Modes are 'channels' of representation or communication (such as writing, image, or sound) that collaborate in communicating messages (Jewitt, 2013). An analysis of different modes emphasizes that each mode has different affordances: characteristics that make them suitable for communicating specific information (Jewitt, 2010). For example, while text is more suitable for narratives, images can be easier to communicate moods and emotions. As modern technology is inherently multimodal in communicating its purpose (integrating text, image, touch,...), it is important to include all these modes of communication into the analysis, integrating them in one holistic study.

Besides the distinction in communicative modes, multimodality distinguishes between three basic communicative functions, called 'metafunctions' (see Table 1 - the terminology is based on Lemke, 2002). These three metafunctions analyze different aspects of communication. While each mode can be analyzed into all three metafunctions, the accent will often be on one specific metafunction. For instance, in a text, the text itself stresses content (the presentational metafunction), while layout contributes to the structure of the communication (organizational metafunction). The multimodal method described below will rely on these metafunctions in order to analyze how the communication of the VLE is structured. 


\begin{tabular}{|l|l|}
\hline Metafunction & Communicative function \\
\hline Presentational metafunction & $\begin{array}{l}\text { What is presented? Which aspect of reality is } \\
\text { represented? }\end{array}$ \\
\hline Orientational metafunction & $\begin{array}{l}\text { Who is involved? How are social } \\
\text { relationships constructed between actors and } \\
\text { stakeholders? }\end{array}$ \\
\hline Organizational metafunction & $\begin{array}{l}\text { How is the communication structured as a } \\
\text { coherent entity that makes sense? }\end{array}$ \\
\hline
\end{tabular}

Table 1. Metafunctions in multimodal social semiotics.

\subsubsection{Meaning potential}

Besides modes and metafunctions, we will rely on the concept of meaning potential in our discussion of users' technology appropriation. Multimodality assumes that semiotic resources do not have a fixed meaning, but have a signifying potential (Van Leeuwen, 2005). As such, meaning potential is a concept similar to affordances, but with an emphasis on interpretation and meaning-making, instead of perception: it explicitly focuses on differences in (social) meaning. The meaning potential of a technological artefact is the sum of all possible uses and meanings of that technology (see Figure 1). Within these possible uses and meanings, multimodality focuses on common meanings and uses that have already been introduced into society (the realized meaning potential - B in Figure 1): for example, using turntables to play music is such a common use. The 'model user' behaviour (Eco, 1979; Derboven et al. 2013, 2016 - A in Figure 1) is part of this already realized meaning potential. While this inscribed model user and social rules typically regulate user behaviour, novel user tactics and appropriations do occur, and can be seen as an extension of the meaning potential in new directions (arrow D in Figure 1, reaching out into C: the unrealized meaning potential). For instance, using turntables for the innovation of 'scratching' (Goldberg, 2004), 'invented' in the 1980s, was once a new appropriation (arrow D), extending the known uses (B) of turntables to produce unknown, new sounds (C). Eventually, however, scratching moved on to become a common part of the rhythmic vocabulary of hiphop and rap music (B).

In our view, design strategies constitute the way in which the 'model user' (A) is inscribed in technology. User tactics are analyzed as the users' realization of the meaning potential in specific, situated use. As such, we can analyze appropriations and user tactics as the realization of meaning potential that extends (arrow D) the already realized meaning potential.

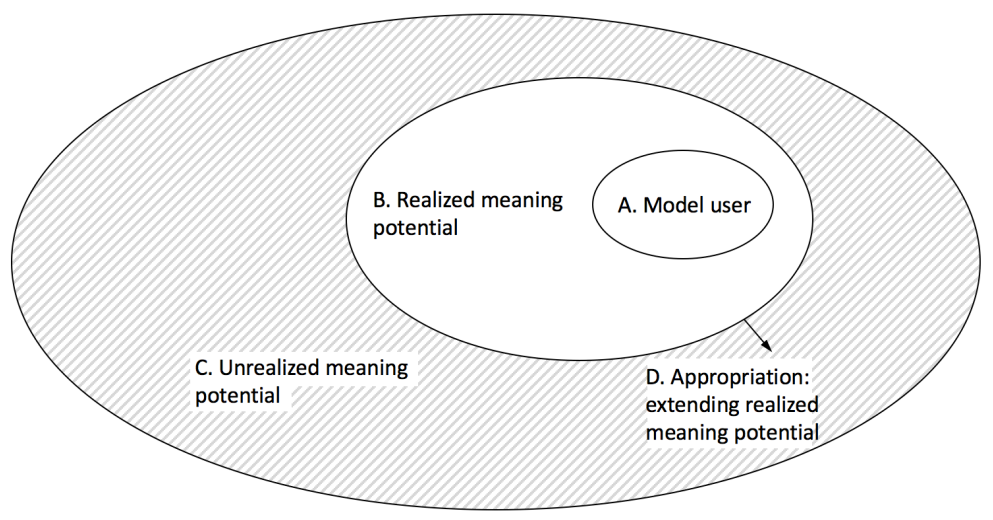

Figure 1: Meaning potential. 


\section{Case Study}

In this paper, we discuss a case study of teachers' appropriations of the VLE used at the KU Leuven Association in Belgium. The VLE is called Toledo: it is a platform developed specifically for the KULeuven Association, and is based on the Blackboard software. The platform has been available at the institution since 2001, at first only at KU Leuven. Starting in 2004, however, Toledo has evolved into the common VLE across all institutions that belong to the KU Leuven Association. As such, it is currently used by some 130.000 users across 13 institutions (KU Leuven, 2012). On the website, Toledo is promoted as a tool for students and teachers which can be used as an information tool, a communication tool, and an evaluation tool. Specifically for teachers, there is a wide range of information available, including online help, workshops on using Toledo in class, and a helpdesk. Although the platform is used in specific departments to facilitate distance learning, teachers use the platform primarily in a blended learning setting, complementing face-to-face lectures. This blended learning setting is also the focus in the present study.

As a widespread VLE, used by a large number of teachers in universities and university colleges across Flanders, Toledo presents an interesting case to study how teachers across organizations and disciplines engage with their institution's VLE. Specifically, we will analyze how the users appropriate the platform, coping with the constraints and structures inherent in it.

\section{Method}

This section describes the method we used to investigate teachers' appropriations of the VLE. As shown in Figure 2, the method consists of two distinct analytic phases. The first phase analyzed the design strategies embedded in the application. Inspired by multimodal analyses of interactive technology (e.g., Djonov and Van Leeuwen, 2013; Djonov and Knox, 2014; Zhao et al., 2014), this phase is based on an analysis of the three metafunctions identified by multimodality (see 3.2.1). These metafunctions play a central role in the analytic process of phase one, as they provide a framework to analyze the ways in which a design communicates.

In the second phase, the meaning potential realized in everyday interactions and appropriations was investigated through ethnographic methods (Blomberg \& Burrell, 2012). As user tactics, the user behaviour was analyzed as contextualized user appropriations in response to the application's design strategies uncovered in phase 1 (see also, e.g., Zhao et al., 2014). We analyzed the VLE appropriations in order to determine whether the observed practices were idiosyncratic, or whether the appropriation tactics can be generalized to other, similar practices. Based on this understanding of appropriation practices, we formulate design recommendations for the design of future VLEs. 


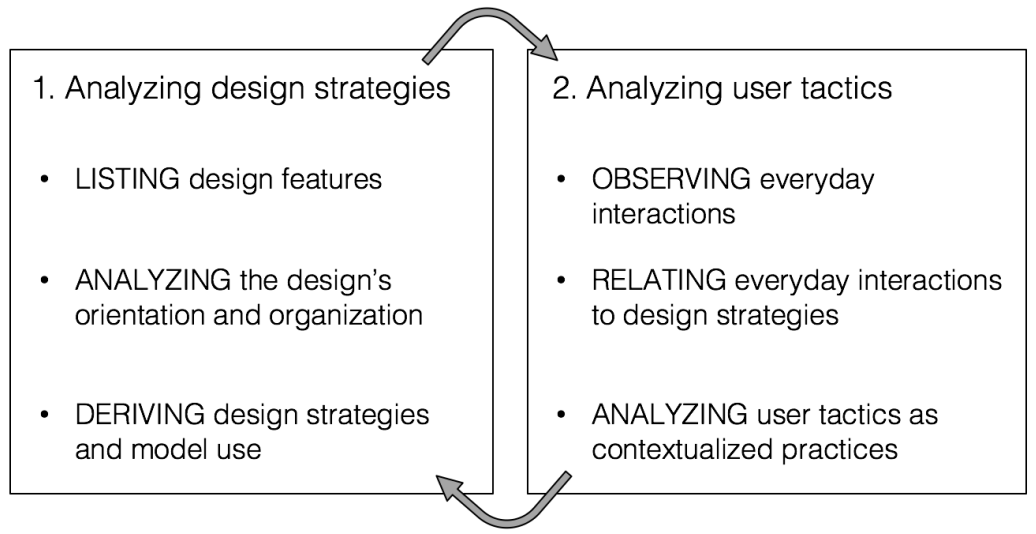

Figure 2: Analytic phases.

\subsection{Analyzing Design Strategies}

In the multimodal analysis, we study the design strategies in Toledo by focusing on the way different modes work together in a 'multimodal ensemble' (Kress, 2010), and how signs motivated, 'semiotic traces from which meanings can be read' (Jewitt et al., 2016: 82) - add up to design strategies that guide users. After a first, general exploration of the platform, we concentrated on an analysis of the design features and metafunctions of the main Toledo functionality: the start page, and the individual course pages, including the default functionality available in the course. This analysis was carried out in an iterative way: after the user study (described in 5.2), we returned to the analysis phase, for a more detailed analysis of the specific tools that were mentioned and used by the respondents.

\subsubsection{Listing Design Features}

In this first part of the design strategy analysis, we explored the platform as a whole. After this general exploration, we listed the various functionalities and tools of the VLE, providing a basic description that could be used for further, more thorough analysis. Differentiating between different modes, we analyzed how the features and functionalities are communicated (e.g., visually, textually). As such, we describe both functional and non-functional (visual, aesthetic) aspects of the design, and specify the actions that can be performed with the design. In this stage, we analyze the various elements present in the application, which features it offers, and how these features are communicated. This basic analysis is based on the first of three metafunctions in multimodality: the presentational metafunction. When listing design features, relevant questions for analysis are (see also Djonov and Knox, 2014: 175): What does the technology consist of? Which features does the technology have? Which features stand out? In which modes are the various features communicated?

\subsubsection{Interpreting Orientation and Organization}

After listing the design features, we analyzed the design's two remaining metafunctions: the orientational and organizational metafunction. Here, the analysis focused on how the application presents itself as a coherent whole, allowing for actions and activities with specific social relationships between actors.

The orientational analysis focuses on social relations: which users and/or stakeholders are (implicitly or explicitly) involved in the interaction. The relationship between these stakeholders, and the role the VLE plays in this relationship is analyzed. The focus is on social consequences of various user roles: Toledo implicitly shapes the communication and relationships between different roles (e.g. teacher vs. student, an active, contributing role vs. 
a more passive, consuming role). These aspects are analyzed as part of the orientational metafunction. Relevant questions for this type of analysis are (see also Djonov and Knox, 2014: 175): Which envisioned 'users' or other actors are involved in the use of the technology, directly and indirectly? Which stakeholders are not represented, or only implicitly? What are the relationships among these actors, and how does the artifact mediate between them?

The organizational analysis focuses on how the application as a whole is constructed as a coherent technology: how individual parts of a message create a meaningful, coherent unity. The organizational metafunction is what ties different parts and modes together, integrating them into a whole. We analyzed how different modes work together in order to communicate a message (i.e., the coherence between modes): do they confirm and reinforce each other, or contradict each other. In Toledo, we investigated how the functionalities, features and tools are linked, and how these links are presented to the users. Additionally, we focused on how the diversity of tools is presented as a coherent unity within the VLE. Relevant questions for this type of analysis are (see also Djonov and Knox, 2014: 175): How are the various features and attributes brought together into one artefact? How does the technology constitute a meaningful whole (application, tool, etc.)? How are specific messages confirmed and reinforced (highlighted) across modes? Does the analysis lead to contradictory interpretations across modes?

\subsubsection{Deriving Design Strategies and Model User}

Based on the metafunctional analyses described above, the 'analyzing design strategies' phase culminates in a meta-analysis of how design strategies are used in Toledo. The findings show how the VLE presents its features and functionality (listing design features) in a coherent way (interpreting organization), involving specific user roles or stakeholders (interpreting orientation). In Toledo, these elements combine into a specific view on teachers, students, learning, and learning activities: these are the values embedded in the application, in Pereira's (2013) terminology. The analysis makes clear how design strategies embedded in the VLE create an ideal, envisioned model user.

We used a hermeneutic approach $(E c o, 1992)$ in order to validate our analysis: we checked the analysis of individual modes and metafunctions against the interpretation of the platform as a whole, and vice versa. Considering that the individual modes collaborate to communicate the same message, it is the coherence between low-level and high-level analysis that validates the overall analysis. Relevant questions that are answered are: Which view on the application domain / user is expressed in the application? Does this view impact how the application guides the interaction with the user? How?

\subsection{Analyzing User Tactics}

\subsubsection{Observing Everyday Interactions}

In the user research, we investigated real users' interactions and appropriations of Toledo: how teachers use the VLE, and how they interpret it from their specific point of view (see also e.g. Van Leeuwen, 2005). The Toledo field study consisted of a qualitative study with 24 teachers from different faculties: the respondent group was selected from teachers that responded to a call for participation, preserving an equal representation of gender, institution, role, and experience with the VLE (based on an assessment of the variety of tools they used in the platform) - see Table 2. Their age varied from young graduates (aged 20-30) to experienced lecturers and professors (aged 50-65). 
Data collection consisted of two parts: a two-week diary study, and extensive, in-depth interviews accompanying the diary study. During two weeks, 20 respondents filled in an elicitation diary (Lazar, Feng, \& Hochheiser, 2010), to enable a discussion of specific practices in detail during in-depth interview sessions. 4 respondents only participated in the interviews, as their Toledo activities were too limited during the diary study period. The interviews consisted of two main parts, and was split up in two separate interviews of 45 minutes, or consisted of one session of $1-1,5$ hour at the end of the diary study.

- The diaries were distributed towards the end of the second semester of the academic year: respondents were asked to fill in the nature of their activities each time they logged into the platform. The diary gathered detailed information about the respondents' activities in Toledo, and a subjective assessment of the sessions. See Appendix A for the list of diary questions.

- When delivering and collecting the diaries, semi-structured interviews were held (see Appendix B for the interview guide). The interviews started from general questions concerning the respondents' personal experience in Toledo, their approach to teaching, and how Toledo is managed in their department. The diary entries allowed for a more specific discussion of their personal VLE practices. Here, interview questions depended on the content of their diary, elaborating upon specific practices. In order to minimize a potential bias based on a limited two-week study, the interviews also included a discussion of how the respondents' VLE use (both the frequency of use, and the nature of their tasks) evolves over the course of an academic year.

The diary contents and interview transcriptions were analysed through a grounded theory methodology: the data was summarized in open-ended codes, which were in turn grouped together into themes. In these themes, various uses and appropriations of Toledo emerged.

\begin{tabular}{|l|l|l|l|l|}
\hline Resp. & $\mathrm{M} / \mathrm{F}$ & Experience & Institution / faculty & Role \\
\hline R1 & F & Basic & University - Arts & $\begin{array}{l}\text { Internship supervisor } \\
- \text { teacher }\end{array}$ \\
\hline R2 & M & Basic & University - Biomechanics & $\begin{array}{l}\text { PhD student teaching } \\
\text { practical sessions }\end{array}$ \\
\hline R3 & F & Basic & University college - Education & $\begin{array}{l}\text { Internship supervisor } \\
- \text { teacher }\end{array}$ \\
\hline R4 & F & Advanced & $\begin{array}{l}\text { University college } \\
\text { Management }\end{array}$ & Teacher \\
\hline R5 & F & Moderate & University college - Economics & Teacher \\
\hline R6 & M & Moderate & University college - Informatics & Teacher \\
\hline R7 & F & Moderate & $\begin{array}{l}\text { University college } \\
\text { Management }\end{array}$ & Teacher \\
\hline R8 & M & Moderate & University college - Arts & Teacher \\
\hline R10 & M & Moderate & $\begin{array}{l}\text { University college - Industrial } \\
\text { sciences }\end{array}$ & Teacher \\
\hline
\end{tabular}




\begin{tabular}{|c|c|c|c|c|}
\hline R11 & $\mathrm{F}$ & Moderate & $\begin{array}{lll}\text { University } & \text { college } & - \\
\text { Management } & & \end{array}$ & $\begin{array}{l}\text { Internship supervisor } \\
\text { - teacher }\end{array}$ \\
\hline R12 & $\mathrm{F}$ & Moderate & $\begin{array}{lll}\text { University } & \text { college } & - \\
\text { Management } & \end{array}$ & Teacher \\
\hline R13 & $\mathrm{F}$ & Advanced & $\begin{array}{l}\text { University }- \text { Pharmaceutical } \\
\text { sciences }\end{array}$ & Internship supervisor \\
\hline R14 & $\mathrm{M}$ & Power user & University college - Education & $\begin{array}{l}\text { Teacher - e-learning } \\
\text { coach }\end{array}$ \\
\hline $\mathrm{R} 15$ & $\bar{M}$ & Power user & University college - Informatics & Teacher \\
\hline R16 & $\mathrm{M}$ & Power user & University college - Nursing & $\begin{array}{l}\text { Teacher - e-learning } \\
\text { coach }\end{array}$ \\
\hline $\mathrm{R} 17$ & $\mathrm{~F}$ & Moderate & University college - Psychology & Teacher \\
\hline R18 & $\mathrm{F}$ & Basic & $\begin{array}{l}\text { University college - Business } \\
\text { studies }\end{array}$ & Teacher \\
\hline R19 & $\mathrm{F}$ & Advanced & University college - Education & $\begin{array}{l}\text { Internship supervisor - } \\
\text { teacher }\end{array}$ \\
\hline R20 & $\mathrm{F}$ & Basic & $\begin{array}{l}\text { University college }- \text { general } \\
\text { staff }\end{array}$ & $\begin{array}{l}\text { International Office - } \\
\text { Internship } \\
\text { administration }\end{array}$ \\
\hline R21 & $\mathrm{F}$ & Power user & $\begin{array}{l}\text { University college - Industrial } \\
\text { sciences and technology }\end{array}$ & $\begin{array}{l}\text { Teacher - e-learning } \\
\text { coach }\end{array}$ \\
\hline R22 & $\mathrm{F}$ & Advanced & $\begin{array}{l}\text { University college - Business } \\
\text { studies }\end{array}$ & $\begin{array}{l}\text { Teacher - Internship } \\
\text { supervisor }\end{array}$ \\
\hline $\mathrm{R} 23$ & $\mathrm{~F}$ & Moderate & University - Language institute & Teacher \\
\hline R24 & M & Basic & University college - Chemistry & Teacher \\
\hline
\end{tabular}

Table 2: Overview of respondents.

\subsubsection{Analyzing User Tactics: Relating Everyday Interactions to Design Strategies}

In analyzing the results from the user study, we focused on the relation between the VLE and the users' experience by relating the design strategies (phase one) to the user tactics emerging from the user study described above. The users' tactics and appropriations are related to the users' 'reading path' (Kress, 2003): the order in which users 'read' and use an application. The users' view on Toledo is shaped by the interactive choices they make in the platform, as they are the basis for interpretation.

When the user tactics focused on aspects that were still underexplored in the design strategies analysis, we elaborated these analyses in more detail: in this way, the analyses are part of an iterative process, going back and forth between design strategies and user tactics.

The analysis of everyday interactions resulted in an overview of situated practices, in which the meaning potential realized by users coincided with, or deviated from the model user behaviour. Where users deviated from the model user behaviour, the rich diary and interview data provided details on how both individual and contextual factors contributed to the development of user tactics and shifts in meaning. Furthermore, the analysis of user tactics in 
relation to design strategies allows for an analysis of the structural logic (Gardiner, 2000) underlying individual appropriations. The aim here is to to uncover underlying patterns of use in order to formulate design implications.

\subsubsection{Analyzing Social User Tactics}

Unless their use is highly personal, users need to communicate (implicitly or explicitly) about their user tactics in order to make their practices meaningful for other users or stakeholders. Focusing on the social context in which the user tactics are developed and used, we analyze how users use 'social tactics' to negotiate, or communicate their shifts in meaning potential to other users or stakeholders. This analysis of how users present their appropriations to others offers valuable information on how they interpret their own behaviour (e.g., as self-evident, as a practical workaround, or as tricks), and how they motivate it. Specifically concerning an environment that allows for tailoring and end-user development, these social tactics show how teachers engage in either individual or collaborative bricolage (see also Pipek and Kahler 2006), and how they communicate about this bricolage with other stakeholders.

\section{Results}

\subsection{Analyzing Design Strategies}

As explained in section 5.1, we offer an analysis of the Toledo platform, and how it structures interaction with its users. This analysis will be the starting point for an assessment of how teachers and students appropriate the platform for their purposes. As it is beyond the scope of this paper to discuss all tools separately, we will offer an overview of the entire platform, and how it is structured.

\subsubsection{Listing Design Features}

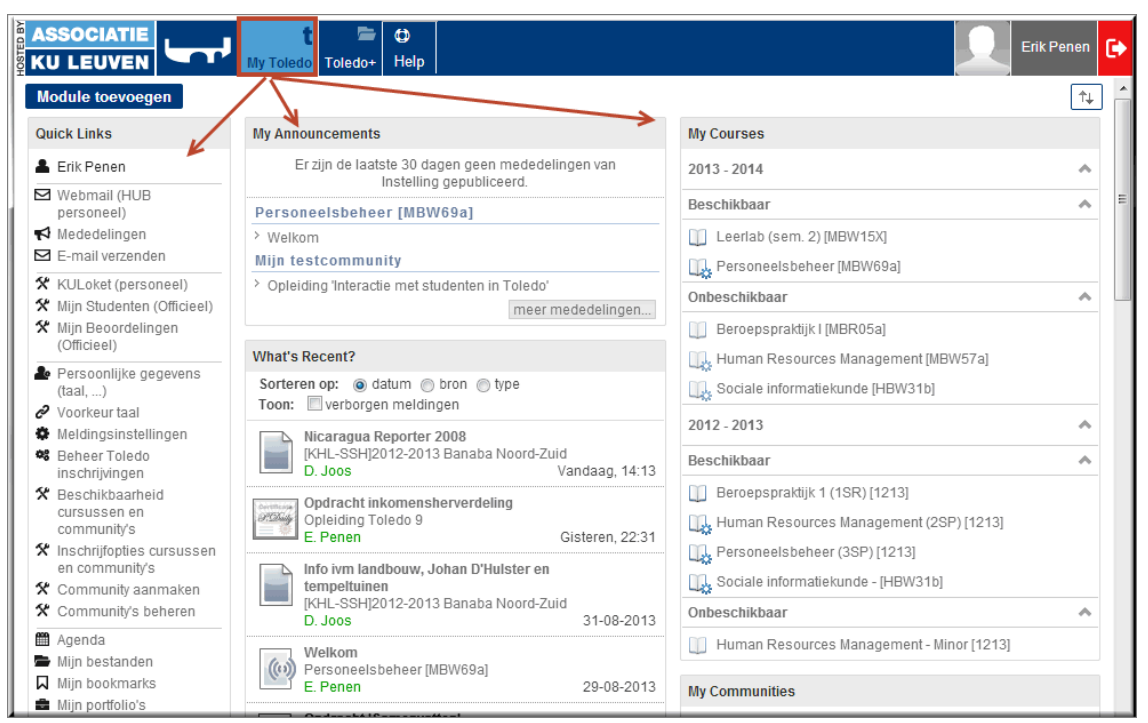

Figure 3: Toledo start page

From Toledo's personalized start page ("My Toledo"), users can access all further functionality. It offers a header (see Figure 3) with links to "My Toledo" (the start page), "Toledo+" (a separate portfolio application), and help functionality. On the top right, login information is available.

The "My Toledo" start page is structured in several modules that offer shortcuts to specific functionalities in the platform. This functionality can be categorized in two main groups: 
course-specific functionality, and more general functionality not linked to a course. By default, the start page is organized in three vertical content zones (see the arrows in Figure 3):

- On the left, a "Quick Links" navigation bar offers access to the general functionality. Tools here include web mail, a calendar, bookmarks, etc. Settings pages include user preferences, and the management of courses (e.g., managing their availability and student subscriptions).

- The modules on the right offer direct access to specific courses.

- The central, most prominent modules, 'My Announcements' and 'What's Recent?', offer an overview of recently added, course-specific information and communication.

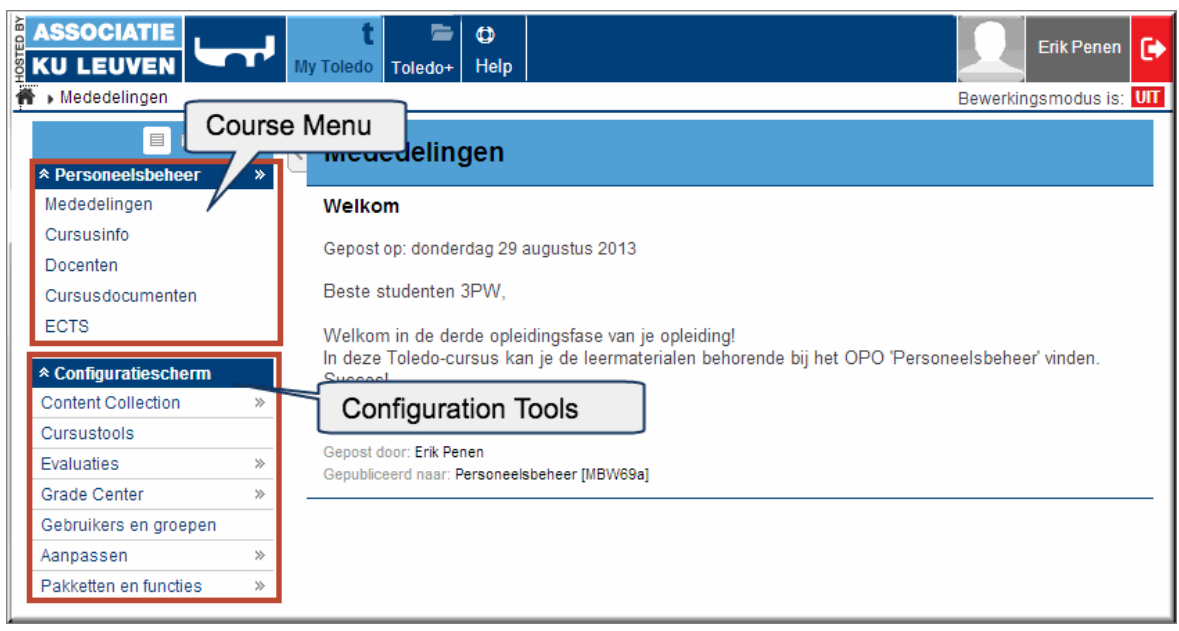

Figure 4: Course page.

Besides the start page, the makeup of courses is also relevant to determine how Toledo structures its communication. A course page (Figure 4) consists of a navigation bar on the left with a course menu and extra configuration tools, through which all content and functionality for that course can be accessed. There is a content zone on the right, in which student announcements are opened by default.

- The course menu section shows the course structure. A new Toledo course offers a limited set of basic functionality (Figure 5). While this structure can be adjusted, by default, it includes announcements for students, links to course materials ('cursusdocumenten') and other information, such as ECTS information. Only the "Tools" link does not lead directly to specific content, but to a long, unstructured list of teaching tools (Figure 6). This list shows the actual diversity and flexibility of Toledo: there is a wide variety of collaboration tools, including discussion boards, chat, wikis, journals, etc. This variety makes Toledo an open, flexible platform, which can support various teaching styles. In this sense, the VLE provides a general structure which teachers can customize by adding content and selecting teaching tools.

- Below the general course navigation, a set of additional tools is available for teachers, including tools for managing the course material ("Content Collection"), for evaluating and grading students ("Grade Center"), and for creating student groups. 


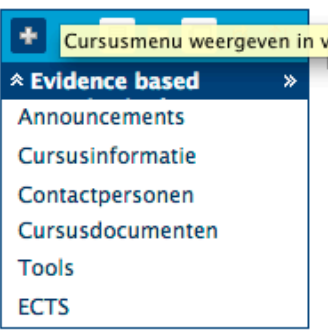

Figure 5: Left navigation bar of a respondent's course (in Dutch), consisting of the default menu structure of a course (top) and links to more detailed course settings in the control panel ('configuratiescherm' - bottom).

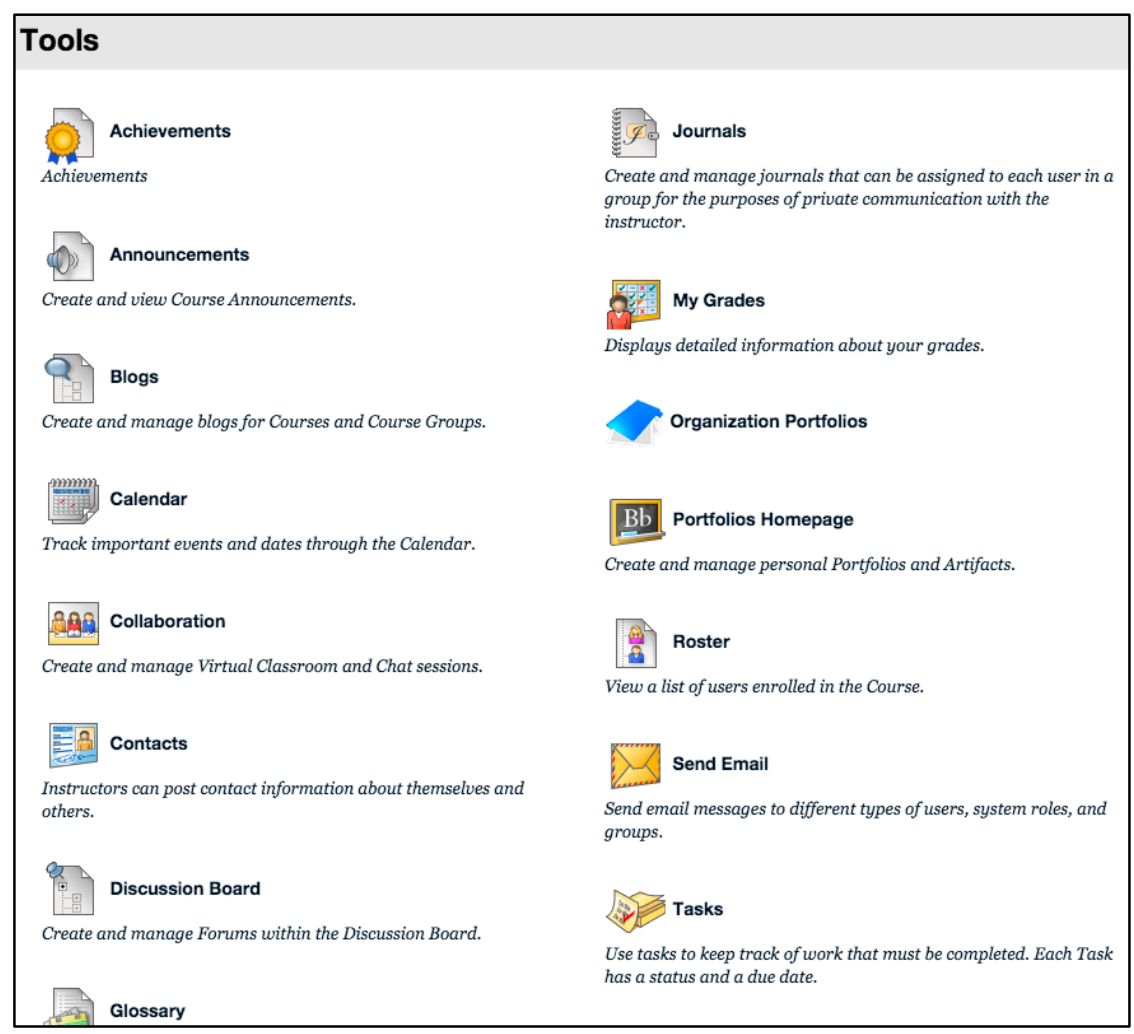

Figure 6: Unstructured (alphabetical) list of available tools.

The overview of design features and functionalities presented above makes clear that Toledo makes information transfer stand out through layout and structural choices. On the Toledo landing page, new announcements and recent changes stand out; similarly, on course landing pages, the new announcements are shown by default. Visually, there is little differentiation between different types of information. The platform has a uniform visual design, which uses various shades of blue and grey to stress the corporate identity of KU Leuven, and leaves little room for a visual separation between the various tools and courses.

\subsubsection{Orientational and Organizational Analysis}

Toledo mediates its users' orientation towards each other based on different user roles: there are 'teacher' and 'student' roles. Teachers have access to the tools needed to set up and manage a course (e.g., uploading documents, creating assignments, managing test results). Students can access the documents and tools made available by the teacher. 
To guide teachers in their use, Toledo offers a set of default functionality that primarily addresses information transfer (see 6.1.1): links to announcements for students and course materials have a prominent place in the platform. This choice of functionality is significant: orientationally, it positions the VLE primarily as a way to transfer information from teacher to student - a positioning consistent with Hamilton and Feenberg's (2012) observation that VLEs often stress the automation of activities. While Toledo's 'action potential' (the goals that can be achieved by performing specific actions - Baldry and Thibault 2010: 152) is not limited to only information transfer tools, these tools are emphasized. Teaching tools that afford collaboration and social interaction are backgrounded, and embedded deeper in the navigation structure (Figure 6). In sum, through the default settings, Toledo primarily positions teachers as active senders of information, and students as passive receivers, even though the platform does offer functionality that facilitates interaction.

The default functionality, however, not only positions Toledo as primarily an information transfer platform: it also provides a basic structure. Organizationally, information linking (see, e.g., Van Leeuwen, 2005) and visual design are the two cohesive devices that stand out when analyzing the platform. The tools in the platform are interlinked in various ways: assigments and tests appear in the 'Grade Center' for assigning grades, student groups created in one tool can be used in other collaboration tools, etc. However, while this structural coherence is present, the links between different tools only become apparent after interacting with them. Similarly, the teaching tools are not structured into e.g. activity types, but they are offered as an unstructured list (Figure 6). As such, the links between tools and functionalities remain implicit: structuring the content is left to the teachers.

Due to this implicit information linking, the uniform visual design becomes one of the most prominent unifying elements used in the platform. The design, as a separate mode of communication, has various roles: orientationally, it stresses the 'brand' KU Leuven: layout customization is limited, making all courses look quite uniform. Organizationally, the uniform visual design presents Toledo as a coherent unity. Moreover, from a multimodal perspective, the uniform visual design of Toledo contrasts with its functional possibilities. While the platform offers a wide variety of tools, this diversity contrasts with the design, which leaves little room for a visual separation or linking between tools and courses. The impression of uniformity is further strengthened by the prominence of the informationtransfer functionality in the default course design. The combination of the visual design, the information linking and the default structure creates the initial impression that the platform focuses only on a uniform set of information transfer functionalities.

\subsubsection{Deriving Design Strategies and the Model User}

Based on the metafunctional analysis, we were able to determine how Toledo uses design strategies to project a specific view on learning, learning activities, and the role of teachers. The analysis of design features and functionality showed that Toledo is a flexible platform, allowing for extensive user configuration of a wide variety of tools. However, organizationally, the platform offers little explicit information on how the various tools are, or can be interlinked. This opens up opportunities for teachers to make their own selection of tools, and link them in the ways that they see fit. By making different selections of tools, activities, or content types, teachers can set up courses in radically different ways.

While the limited information linking can be an opportunity, it can also be a threat. Orientationally, the limited subset highlighted as default functionality stresses the platform's information-transfer function, and therefore positions teachers as active senders, and learners as passive receivers of information. This focus on information transfer, combined with a uniform visual design creates a first impression of a static platform that primarily stresses 
automation of learning-related activities, rather than social interaction (see Hamilton and Feenberg, 2012). The flexibility of the platform only becomes clear after further exploring the variety of tools, and the links between them. As such, design strategies point towards a double 'model user'. For novice users, the default information transfer functionalities create an impression of a static platform, while more experienced users can explore the functional diversity of the VLE more fully. Due to the implicit information linking strategy, experienced users are not guided towards a specific setup of tools, but are free to combine tools and functionality in various ways. In sum, depending on the users' familiarity with the platform, it highlights a different set of values (Pereira et al., 2013). While for advanced users, the platform promotes values of adaptability, collaboration, and conversation, the default functionality set, combined with the static appearance of the platform project a rather rigid platform that stresses one-way communication.

\subsection{Analyzing User Tactics}

Based on the analysis of Toledo, we analyze the various user tactics we encountered during interviews with teachers, and relate them to both design strategies and contextual factors. As such, we will analyze the underlying, collective or structural logic (Gardiner, 2000) that underpins the individual appropriations.

\subsubsection{Self-Declared 'Modest Users'}

10 out of 24 respondents explicitly mentioned they saw themselves as 'modest users' of the Toledo platform, meaning that they used only a small portion of the functionality available. In table 2 (see 5.2.1), these respondents are categorized as either basic or moderate users, based an assessment of the variety of tools they use in the platform. Their self-assessment, however, was based on the awareness that the platform has many more possibilities: even though most teachers were aware of resources such as the online help, and Toledo workshops, time limitations were often mentioned as a reason for the lack of more elaborate use. This finding confirms previous research, indicating that lecturers often use a limited amount of 'classical' tools such as document repositories and discussion boards over more advanced features (Hemmi et al., 2009; Veletsianos et al., 2013). Apart from the time aspect, the interviews with teachers revealed two other reasons to stick to a limited set of functionality: a lack of knowledge of the platform, and the appropriation of other alternatives, both within and outside Toledo.

To some extent, the lack of knowledge about the platform can be related to the large amount of tools and functionalities that is offered, and the implicit information linking. Due to this extensive choice of tools, teachers tend to be satisfied with what they already know, instead of further exploring possibilities. In this way, the 'reading path' they trace through the application remains limited to a few tools they know: teachers are not stimulated to explore other tools. For instance, R17 did not know how to implement student portfolios in Toledo, and R24 knew Toledo could be used to create tests, or divide students into subgroups, but did not know how. As he used other ways to achieve his goals (e.g., forming student groups using documents in Google Drive), he was satisfied with his way of working. This lack of exploration is even more noticeable when users are no longer aware of the existence of some of the tools. This was the case for R7, who used peer assessment in her course, but was unaware that a dedicated peer assessment tool was available in the platform.

Alternatives outside Toledo were used by more than half of the respondents (16 out of 24) to offer learning activities or course content. Some of the respondents reported using dedicated applications related to the subject matter of the course (e.g., R20 using a cross-media journalism platform), but the majority (14 respondents) used other applications for other 
reasons. For instance, they switched to dedicated platforms to manage internships because Toledo did not support their specific needs (R11, R13, R15, R22), or because other applications were considered easier to use (e.g., R15 using Tumbr instead of Toledo blogs). This widespread behaviour of using alternative applications that seem more suitable need not surprise, as it can be related to teachers' general tendency to engage in 'bricolage', considering how the tools they have at hand can be used to serve their needs (Hatton, 1988). Teachers engage in bricolage here, by compiling learning activities with a variety of applications that seem most suitable.

\subsubsection{Appropriating Toledo Functionality}

Teachers not only appropriated applications and tools outside Toledo, but also tools within the platform. The analysis of user tactics showed that 8 respondents deviated from the model user behaviour to various extents. Several tools were appropriated: for instance, R1 and R23 used the discussion board to let students upload their assignments (despite the existence of dedicated assignments tool), and R23 also used it as a 'portable language lab' (as she called it). The assignments functionality was, in its turn, used to let students submit internship contracts and documents (R22) or peer assessments (R7), despite the dedicated peer assessment tool. R4 organized student portfolios using the Journal functionality. As a means to communicate test results, R19 used the platform's e-mail functionality, and R11 uploaded a spreadsheet with all results to the document repository. These appropriations were personal appropriations developed by the teachers themselves, except for R22's appropriation (submitting internship documents using the assignments functionality), which was a collaborative effort of the teachers within the department.

At first sight, these appropriations seem to be a rather heterogeneous mix. However, looking closer, two common aspects are striking. First, almost all the specific uses targeted by the appropriations above (peer assessment, submitting assignments,...) have dedicated tools in Toledo. In other words, the respondents appropriated tools in the VLE, instead of using the dedicated functionality available in it - either because they did not know about the existence of the dedicated functionality (e.g., R7, unaware of the existence of a peer assessment tool), or because the dedicated functionality did not completely satisfy their needs (e.g., R1 using the discussion board to let students upload assignments). Second, the tools that were most often appropriated in our study were not the tools offering very specific functionality, but more generic communication tools, such as the document repository or the discussion board. These communication tools, facilitating teacher-to-student (document repository), student-tostudent (discussion board), or student-to-teacher (assignments) communication, have a broader meaning potential than more specific tools (such as the peer assessment, or the portfolio tool), as they impose fewer limits on their use. Some dedicated tools restrict use in specific ways (e.g., the peer assessment tool didn't allow R21 to group students in an appropriate way), narrowing down their meaning potential, and making them unsuitable for some purposes. In contrast, the more generic communication tools are more open-ended in their design. For instance, the discussion board only imposes limits on the direction of communication (orientational metafunction), not on other specific aspects like the communication content (presentational metafunction).

This observation adds an important nuance to the self-declared 'modest users' of Toledo (using only a small portion of the functionality). While it is true that these teachers only use a limited number of tools, this does not mean that they only use the platform for very basic learning activities. On the contrary, some of the 'modest users' appropriated basic tools for very specific learning activities (e.g., R23 using the discussion board as a 'portable language lab'). Moreover, as the respondents that reported this behaviour came from various 
backgrounds and faculties, this appropriation of tools with a broad meaning potential seems to be a common appropriation practice across departments and institutions.

\subsubsection{The Case of the Discussion Board}

We will use the discussion board as a case study to discuss appropriation practices in detail. Using the discussion board as a central case, we will broaden the discussion of specific appropriation aspects to other cases and tools outlined in 6.2.2.

Respondents mentioned the use of the discussion board in various contexts, both for the more 'traditional' discussion activities, as for specific appropriations. The discussion board allows users (both teachers and students) to create topic threads, and post or reply to messages in these threads, also offering the possibility to add attachments to messages. In sum, the discussion board is a structured, topic-oriented discussion board targeted at asynchronous discussion. Half of the respondents (12 out of 24) reported having tried to incorporate the discussion board functionality in their teaching. Most of them (10 out of 12), however, reported little success, or variable success rates.

R9: What I notice, is that they use it [the discussion board] for one week, and then they move their activities to Facebook. [...] They feel the Toledo discussion board is too rigid, not flexible enough, not practical enough. So Facebook is more useful for that.

In general, two types of reasons were reported for the slow uptake of the discussion boards. The first one is exemplified by the quote above: the discussion board is considered to be too rigid, and inflexible. In other words, the structure of the tool, with its asynchronous and structured way of commenting and replying is too inflexible for students, who are used to very lightweight communication via Facebook and other social media. This student behaviour is similar to the teachers' bricolage described in 6.2.1: the students move to other tools. The second reason mentioned by the teachers was social: the fact that students feel uncomfortable having online discussions which the teachers can monitor.

Looking at teachers' discussion board appropriations, however, another picture emerges. Both R1 and R23 used the Discussion Board to let students upload assignments, in a very structured way - although a dedicated assignments tool is available. Especially R23 used a highly structured process in which students in an academic writing course upload their texts ('originals'), which are then reviewed by two of their peers, who upload their reviews in a reply to the original post. Finally, the authors resubmit a final version of the assignment.

R1: For example, we let students submit an assignment using a forum. Actually, that is not the usual way to submit an assignment. [...] It's useful because you can search for students, so you can immediately see who has submitted the assignment. And that is not possible in Grade Center [the dedicated grading tool]. There, I can only use an alphabetic listing.

R23: [...] the idea is that there's a hierarchy [of posts and replies] [...]. There should be five originals. And I usually say: on Monday, five originals. On Tuesday, then there are ten reviews [submitted by other students, who review the originals]. And then, on Wednesday, there are five resubmissions. [...] It's gone through a process [...] So, using the forum, the discussion forum, each tutorial is prepared, and for each tutorial, there's about 25 posts. And everyone should find their way around, because I say, you have to do this labeling system, so it's not e-mails: read this, read that, and there shouldn't be more dialogues than necessary.

Both discussion board appropriations have notable similarities and differences. The appropriations are very similar, in the sense that they both use the hierarchical, relatively inflexible structure, considered a drawback when used for unstructured discussion, as a 
strength in the appropriation. There is a structured, searchable list of assignments, and in the case of R23 even a very structured hierarchy of submissions, reviews and resubmissions. In other words, the design features that prevent the uptake of the tool in one context actually constitute the strength of the tool in a specific appropriation. Such appropriation of tools because of specific design features was also apparent in other appropriations. For instance, R4 mentioned specific design features of the Journal functionality that make journals suitable to organize student portfolios:

R4: Because you can group them [students]. They can create specific documents, items, and create one item per subject they have to address, and create different versions of them. The big advantage is that, as a teacher, you can also give general comments.

In another respect, the appropriations are rather different. R1 asked students to upload assignments for herself to evaluate: this appropriation reuses a 'social' tool for information transfer purposes. In contrast, R23 used a more collaborative structure for uploading and reviewing assignments. The appropriation of R23 adds yet another important element. We argued in 6.2.2 that a discussion board is a generic tool with a broad meaning potential: its design imposes few constraints on communication. However, by implementing a labeling system, a specific hierarchy, and even specific roles for students (R23 mentioned assigning specific student roles, such as a 'postman' in charge of compiling submissions), the use of the discussion board is constrained, not through the design, but socially. The next section will go into more detail on how appropriations with implications for social roles are negotiated among users.

\subsubsection{Negotiating Appropriations}

The discussion of appropriations listed above focused primarily on the way design features have been reinterpreted in order to support specific activities. In other words: the presentational content (see 5.1.1) in the tool changes due to the appropriation - from student discussion to assignments. In some appropriations, however, the orientational aspect (the way the tool mediates between different actors - see 5.1.2) also plays an important role. When an appropriation involves such a shift in orientation, it needs to be made explicit: the appropriation of the tool needs to be renegotiated:

R23: If the teacher could design the look and feel, that would be nice. Because I - for example, my discussion board is not really a discussion board. I suppose I would call that different things. [...] I'd call the discussion board 'coaching area'. So that people... For me, the labeling doesn't matter, the fact that it's a discussion board and I use it as something else, but some people say: 'Oh, but we don't discuss, then. We just post things.' And their expectation is it's going to be chat. And I say: no, we don't actually chat in the discussion board. And then, they seem to think they should.

The reactions on the appropriation of the discussion board make students' expectations explicit: it becomes clear that the discussion board-as-a-submission-system is uncommon, and not a part of the socially accepted discussion board use. As an appropriation that extends the tool's meaning potential, the appropriation needs an extra effort from the teacher to explain it to the students. While the teacher treats the discussion board as a container of information and documents, students interpret it as a tool for communication.

In a similar way, R11 needed to renegotiate the use of the course documents section to upload test results to the platform, as this appropriation also had wider, orientational implications. Where the communication of test results is typically a personal teacher-to-student communication, the course documents section only allows for communication from the 
teacher to all students. This shift in orientation, therefore, needs to be made explicit, and needs to be renegotiated:

R11: [...] but everyone can see everyone's grades. And I ask, at the start of the academic year, whether they have a problem with that. [...] I say: "If you have a problem with that, I would very much like to hear from you." But so far, I have never received an e-mail.

\subsubsection{Stabilizing Toledo Use}

The perception of Toledo as a single platform influenced the way teachers appropriate it. From the organizational perspective, the visual design of the platform is an important aspect that highlights the coherence in the platform. Different respondents reported coping with this uniformity in a different way. Some respondents regretted the uniformity (see the R23 quote below), and even resisted it, moving to other applications. R17, for instance, mentioned creating a separate website for one of her courses, in which she could offer the course material in a way that was both visually and structurally more appropriate.

R23: Students sometimes have different expectations, they have different courses, and if there are ten professors, and one of them doesn't do the same things as the other nine, they say: why don't you do that? It comes with expectations. If it's your own platform, suppose it wasn't called Toledo, but had the name of the department on it, so you could adapt it so some extent $[. .$.$] Now you think: ah, we are 'in Toledo'.$

In the quote above and in the quote in 6.2.4, R23 refers to the visual design of Toledo as an important organizational device: the visual style adds uniformity to the various tools available, and it presents Toledo as a coherent unity. Being 'in Toledo', as R23 says, raises students' expectations. They expect to behave in a certain way, and these expectations need to be revised if the teacher expects behaviour that deviates from that norm. Even among teachers, the Toledo platform comes with expectations based on the visual design. For instance, R14, a Toledo coach, commented on the perception of some of his colleagues:

R14: Last year, I had a meeting with a colleague that went to a training about another platform. "Oh, that was great!" She showed me a building block-like environment: "You can't do that in Toledo." I replied: "Yes, you can. [...]" "Well, I thought you would think this is great," she said, but I replied: "No, that's just a different visualization."

Apart from students' own reactions, and even resistance (in the case of R23's students) to appropriations, several respondents mentioned collaborative efforts among teachers in the same department or campus to use a uniform Toledo structure. This strengthens the platform's organizational structure. As the design strategy of implicit information linking between tools makes for a very flexible platform that does not guide users towards a specific setup of tools, teachers made arrangements to strengthen the platform's coherence across courses. From a structured way to name student assignments (R15) to a uniform course structure, the social agreements surrounding Toledo ranged from small, detailed agreements on nomenclature to general agreements on the entire course structure. This uniform course structure was even formalized across the entire campus of R19, where the Toledo course structure was the subject of a dedicated chapter in the 'vademecum' (handbook) for employees. In this way, the uniformity of Toledo is reinforced not only through design, but socially, through agreements among teachers. 


\section{Discussion}

\subsection{Destabilizing the Platform}

The results show how various functionalities move from dedicated Toledo tools to other tools, both inside and outside of the Toledo platform. While the specifics of the appropriations vary widely, two general moves can be distinguished. The first move is one to other, mostly web-based tools for functionality that is available within Toledo; in the second move, the dedicated Toledo tool is not used, but another, more general communication tool within the VLE is appropriated. As such, the flexible, tailorable application structure, with its design strategy of implicit information linking between tools, becomes an unstable environment due to the fact that specific Toledo functionality is both exported outside the system, and other Toledo functionality is appropriated and moved to other tools.

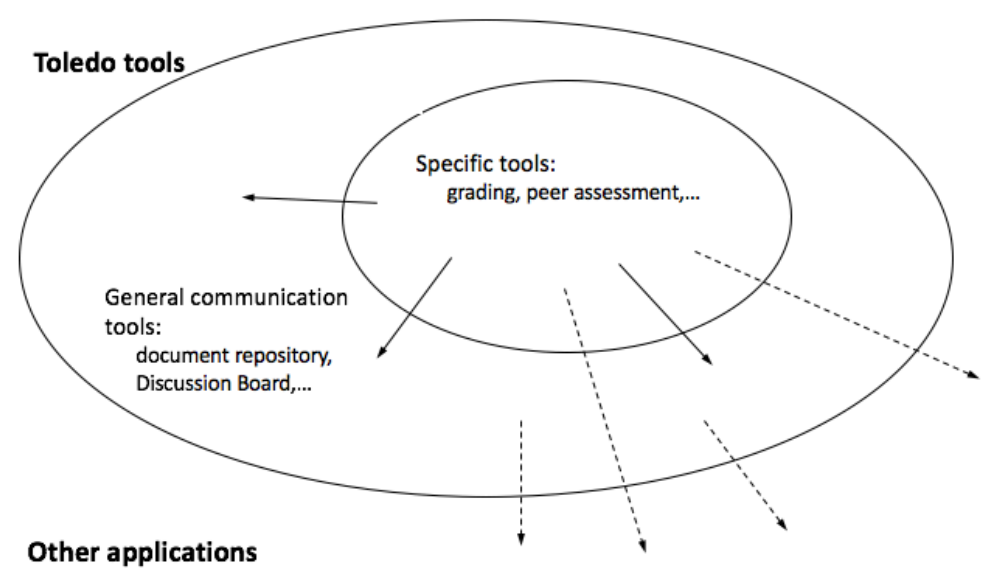

Figure 7: Functionality migration, both internally in Toledo (solid arrows), and from Toledo to other applications (dashed arrows).

This 'functionality migration' both within and outside of Toledo creates a centrifugal force of sorts, destabilizing the VLE (Figure 7). The functionality of specialized Toledo tools (grading tool, portfolio,...) with a more narrow meaning potential is moved to more generic communication tools in Toledo with a broader meaning potential. As the appropriated tool is extended with new interpretations, the platform's reference to the expected model user behaviour (e.g. in naming) becomes meaningless: the connection between a tool's name and the learning activities is lost, as, for example, the 'discussion board' is used as a submission system. For tools with a narrow meaning potention, the opposite is true: the more structure a VLE tool imposes on its users as a design strategy, the less likely it becomes that the tool is useful across a wide range of situated teaching practices (see also Bennett et al., 2015), and the less likely it becomes that it will be used by a large number of users. This has implications for the role and tailorability of specialized tools in a VLE. In Toledo, the design strategies pointed towards a double 'model user' (see 6.1.3): for novice users, the focus is on information transfer functionality, while for more experienced users, the values of adaptability, collaboration, and conversation (Pereira et al., 2013) become more apparent. The results of the user research, however, show that teachers often do not engage in the configuration of additional, specialized tools in the platform, but appropriate generic tools. This means that instead of exploring the system, the reading path of more experienced users 
often remains limited to the 'novice' applications, which they appropriate to fit their needs (see also Christie and Garrote, 2011). The limited use of tools in a VLE is therefore not a simple issue that can addressed by creating additional resources or training (what Star and Ruhleder (1995) have called 'first-order issues'). Instead, it can be seen as resulting from the combination of the bricolage work of teachers and the meaning potential of the tools themselves.

The functionality migration can be seen as a consequence of the open structure and limited information linking of the VLE, offering a wide variety of tools for teachers to pick and choose from. As the open structure offers ample possibilities for use, appropriation and repurposing, a wide range of appropriations and different course setups can be expected. However, individual tools do have their specific, dedicated purpose within the platform: these specific purposes are being destabilized by the functionality migration.

\subsection{Appropriation Tactics}

As bricoleurs, teachers consider how the tools they have at hand can be used to serve their needs (Hatton, 1988). The results above show that when teachers engage in bricolage within a VLE, they primarily consider the direction of communication needed for the learning activity. The document repository, suitable for communication from teacher to student, can be used to make grades available (R11). The discussion board, suitable for communication among students and with equal roles for teacher and students, can be used for submitting assignments (R1 and R23). Therefore, the suitability of general communication tools for bricolage depends mostly on the roles the teacher and the students have in the communication: can they make information available, or can they only read information made available by people with another role, etc.

This focus on the direction of communication shows how functionality of many specific tools can be recreated by appropriating a small set of general communication tools with a broad meaning potential. As the structure imposed by specialized tools can be inappropriate for some teaching situations, a limited uptake of VLE tools is not necessarily a problem or a failure, provided that teachers are able to implement their learning activities by creatively extending the meaning potential of a small set of tools. While Chatti et al. (2007) already argued for 'freeform use of a set of light-weight tools (p. 415), this study provides evidence that users indeed appropriate 'light-weight tools', primarily based on the direction of communication. This result contributes to the current understanding of factors that play a role in how teachers appropriate educational technology. Apart from e.g. pedagogic and institutional factors (Bennett et al., 2011; Berggren et al., 2005), specific design strategies (direction of communication, narrow or broad meaning potential) also influence teachers' appropriation. Based on this analysis, we can formulate design recommendations for future learning environments. As a first recommendation, we suggest that designers should provide a limited set of open, appropriable communication tools, with a broad meaning potential, apart from more dedicated tools and functionalities. Communication tools that are not targeted at specific learning activities allow teachers to adapt them to their specific needs and context. Secondly, when offering these tools, the focus should be on the direction of communication (teacher-student, student-teacher, or student-student). While tools that are targeted at specific learning activities can be structured according to the type of learning activity, the most important characteristic of open, appropriable communication tools is the direction of communication. 


\subsection{Appropriation as a Social Phenomenon}

Even though the appropriations and reinterpretations on a functional level are the most visible, the results showed that users' expectations and appropriations are also mediated and influenced strongly on other levels. In a multimodal combination with the functionality, a uniform visual design plays a significant role in raising social expectations. Appropriations often imply an extension of the application's meaning potential beyond the socially accepted meanings: therefore, they need to be negotiated among stakeholders in order to be understood. Negotiations with students can be necessary, as the Toledo platform 'comes with expectations' about the way it is used by teachers. Students expect to behave in a certain way, and these expectations need to be revised if the teacher expects behaviour that deviates from that norm. Moreover, this negotiation often needs to go beyond the purely functional. Reinterpretation of functionality can have immediate social consequences, as it can reconfigure the relationship between different users or stakeholders. For students, posting test results in the document repository is not only a presentational change in content, but it also changes the orientation (privacy habits are changed by making test results available for all students). Appropriations are negotiated among teachers, as well. The collaborative efforts among teachers in the same department or campus to use a uniform structure show how uniformity is valued over individual appropriation.

These social aspects clearly mediate appropriation and bricolage, and may prevent or aid teachers in developing appropriations. In this sense, the flexibility of a technology can be seen as variable over time: when the use of technology is firmly rooted in social agreements, the flexibility to appropriate diminishes accordingly. Social factors, such as the common understanding of what a platform means, stabilizes the use people make of that platform. In this way, the use and appropriation of a VLE is determined more by practice than by design. In order to support a more stable use of the platform, teachers could benefit from more collaborative forms of tailoring. Instead of engaging in personal bricolage, group-supported tailoring can be an effective way to allow teachers to share appropriations. This leads us to formulate a third recommendation for the design of VLEs. VLEs should provide an environment for collaborative tailoring (Pipek and Kahler, 2006), in order to allow teachers to develop and share their own course and tool templates among colleagues and in departments. In the terminology of Lazar \& Preece (2003), teachers would benefit from not only being 'community leaders' for their students, but also being a member of a teacher community in which VLE practices are developed, shared and refined. In this way, social agreements between teachers and in departments on how to structure course activities can be embedded in the platform itself, instead of being limited to more or less formalized guidelines.

\subsection{Analyzing VLE Appropriation as Design Strategies and User Tactics}

The results have shown that user tactics can be seen as practices in reaction to both contextual factors and design strategies embedded in the technology. As the technology design is an important foundation from which all user appropriation starts, it is worthwhile to analyze it thoroughly: a multimodal analysis is well-suited to this task, as it offers a framework to analyze the meaning potential of the technology from various perspectives (Kress, 2003). However, appropriations are not based exclusively on the technology itself: situated use can be investigated using ethnographic research methods (Kress, 2010). In this view, multimodality and ethnographic methods are complementary (Dicks et al., 2011), as they offer methods that analyze the two main elements on which user interpretation is based: the technology itself, and personal and situational factors. The combination of ethnography and semiotics is not new in itself: Kress (2011) has explicitly identified ethnography as an 
approach complementary with multimodal social semiotics, when analyses of signs or sign systems can benefit from a detailed understanding of the intended receivers of the message. In this study, we have shown how the combination of a multimodal, social semiotic analysis with ethnographic research methods can be useful for investigating appropriation and enduser development. We have revealed how teachers use tactics to reinterpret the tools and structure of Toledo to suit their needs. Specifically, the notion of functionality migration offered novel insights into the way teachers appropriate generic communication tools for specific purposes, limiting their use of VLE functionality to a set of basic tools.

These results also have implications for the research of VLE appropriation in general. The Toledo-internal appropriations make it difficult to capture the use of the VLE. Even though users may report using only a limited amount of tools in the VLE, their use, in practice, can be more sophisticated. This observation nuances existing statistical studies about VLE use: for instance, statistics on the use of the peer assessment tool do not necessarily give an accurate representation of the use of a VLE for peer assessment, as the results have shown that peer assessment can also be implemented using other VLE tools. Statistical studies can capture use, and categorize it in categories that are mostly limited to the design strategies: it is impossible for statistical studies to categorize (often unexpected) user tactics (see also Salovaara 2013). As de Certeau states: "what is counted is what is used, not the ways of using" (1984: 35 - original emphasis) - in other words, in statistical studies, the user tactics often remain unaccounted for.

\section{Limitations and Future Work}

It is important to acknowledge the limitations inherent in this study. We performed an indepth study of the way teachers use and appropriate a VLE. While the method we used is useful for researching the relation between user behaviour and technology of a limited number of respondents, it is not suitable for use with large user groups. The method is especially applicable in in-depth, small-scale user trials of a specific application. We acknowledge that in this article, we focused on one particular case study, and involved a limited small number of respondents. In line with most ethnographically-oriented research, the study relies on its ecological validity (see e.g. Chi 2009). While this means we cannot provide a generalizable picture of appropriation processes of VLEs in general, we do provide insight in the way appropriation tactics are influenced by the design choices in a VLE.

In addition, Toledo, the VLE examined in this case study, is not a static platform. The platform is regularly updated with new or changed functionality, and designs. For appropriation processes, this means that specific appropriations might start in one design, and be carried over to newer designs and functionalities. As appropriation is a process, these platform updates make it difficult to determine the exact origin of appropriations. Therefore, we did not make claims about the ways appropriations come about: we analyzed the interaction between design strategies and user tactics at one specific point in time.

This article focuses on intra-platform appropriations. Future work could explore the interaction between design strategies and user tactics in the larger learning ecosystem, including appropriations of tools outside the VLE. On a methodological level, the added value of the semiotic analysis of design strategies can be further explored by comparing the multimodal semiotic approach with a non-semiotic research approach. 


\section{Conclusion}

Our analysis of the Toledo appropriation by teachers has lead to a more nuanced understanding of how teachers engage in bricolage within their VLE, and customize, integrate and appropriate tools according to their needs. Based on an interpretive methodology combining semiotics with ethnographic methods, we have shown how teachers develop tactics to reinterpret the design strategies embedded in the platform. The results stressed the importance of social processes in VLE appropriation. Appropriations need to be negotiated among stakeholders: between teachers and students, the purpose of appropriated tools needs to be clarified. Among teachers, practices across teachers and courses are negotiated in order to strenghten the coherence in the platform. Based on these results, we have suggested that VLEs can support these social processes by offering course and tool templates in VLEs. By offering adaptable templates, these social agreements can be embedded in the platform itself, instead of being limited to more or less formalized guidelines.

Furthermore, by analyzing the shifts in meaning, and clarifying the underlying mechanisms that underpin appropriation, we contribute a new perspective on the uptake of VLEs by teachers. The study showed how teachers move functionality from specific, dedicated tools to more general communication tools. This finding sheds new light on the observation that teachers often adopt only a limited set of tools and functionalities in VLEs: teachers can appropriate this limited set of basic tools and develop sophisticated learning activities using basic tools and functionalities. Based on these appropriation tactics, we suggest that VLE designers should provide a limited set of open, appropriable communication tools, apart from more dedicated tools and functionalities. These tools can then be appropriated by teachers according to their needs. In these appropriations, the direction of communication (studentteacher, teacher-student, or student-student) is the most important tool characteristic: when offering these open tools, the focus should be on this direction of communication.

Finally, this article shows how multimodal social semiotics can provide a useful framework to research how users tailor flexible environments. The combination of semiotics and ethnographic techniques has enabled us to clarify how a VLE guides the users' actions through its design and structure. In combination with an analysis of user behaviour, this has allowed us to analyze how users cope with the structures and constraints inherent in the technology design, and to clarify the mechanisms that underpin appropriation.

\section{Acknowledgements}

This study is part of a $\mathrm{PhD}$ project funded by iMinds (Interdisciplinary institute for Technology), a research institute founded by the Flemish Government. We thank the Toledo team and Isaline Broes for their help in conducting the user study.

\section{References}

1. Andersen, P.B. (1990). A Theory of Computer Semiotics. Cambridge, MA: Cambridge University Press.

2. Baldry, A., Thibault, P.J. (2010). Multimodal Transcription and Text Analysis. A Multimedia Toolkit and Coursebook with Associated On-line Course. London, UK: Equinox. 
3. Balaam, M. (2013). A Part Practical and Part Conceptual Response to Orchestration. Computers and Education 69, 517-519.

4. Bennett, S., Thomas, L., Agostinho, S., Lockyer, L., Jones, J., Harper, B. (2011). Understanding the design context for Australian university teachers: implications for the future of learning design. Learning, Media and Technology 36:2, 151-167.

5. Bennett, S., Agostinho, S., Lockyer, L. (2015). Technology tools to support learning design: Implications derived from an investigation of university teachers' design practices. Computers and Education 81, 211-220.

6. Berggren, A., Burgos, D., Fontana, J.M., Hinkelman, D., Hung, V., Hursh, A. and Tielemans, G. (2005). Practical and pedagogical issues for teacher adoption of IMS Learning Design standards in Moodle LMS. Journal of Interactive Media in Education 2: 2, 1-24.

7. Bezemer, J., Kress, G. (2008) Writing in Multimodal Texts. A Social Semiotic Account of Designs for Learning. Written Communication 25: 2, 166-195.

8. Blomberg, J., \& Burrell, M. (2012). An Ethnographic Approach to Design. In: Jacko, J.A. (Ed.) The Human-Computer Interaction Handbook. Fundamentals, Evolving Technologies, and Emerging Applications. Third Edition. (pp. 1025-1052). Boca Raton, FL: CRC Press.

9. Chandler, D. (2007). Semiotics: The Basics. $2^{\text {nd }}$ Edition. New York, NY: Routledge.

10. Chatti, M.A., Jarke, M. \& Wilke, D.F. (2007). The future of e-learning: a shift to knowledge networking and social software. Journal of Knowledge and Learning, 3:1, 404-420.

11. Chi, E. (2009) A position paper on 'living laboratories': Rethinking ecological designs and experimentation in human-computer interaction. Human-Computer Interaction. New Trends. 5610: 597-605.

12. Christie, M., Garrote, R.J. (2011). Lecturer engagement in the use of interactive tools in learning management systems. A Swedish case study. In: Proceedings of the Australasian Society for Computers in Learning in Tertiary Education Conference (ASCILITE '11), Hobart, Australia.

13. Conole, G., Dyke, M. (2004). What are the affordances of information and communication technologies? ALT-J, Research in Learning Technology 12: 2, 113 124.

14. De Certeau, M. (1984). The Practice of Everyday Life. London, UK: University of California Press.

15. Derboven, J., Geerts, D., \& De Grooff, D. (2013) Researching user interpretation beyond designer intentions. In CHI EA 2013. New York, NY: ACM Press, 367-372.

16. Derboven, J., Zaman, B., Geerts, D., De Grooff, D. (2016). Playing Educational Math Games at Home: The Monkey Tales Case. Entertainment Computing 16: 1-14. 
17. De Souza, C. S. (2005). The Semiotic Engineering of Human-Computer Interaction. London, UK: The MIT Press.

18. Dicks, B., Flewitt, R., Lancaster, L., \& Pahl, K. (2011). Multimodality and Ethnography: Working at the Intersection. Qualitative Research 11, 227-237.

19. Djonov, E., Knox, J.S. (2014). How-to-analyze webpages. In Interactions, Images and Texts. A Reader in Multimodality. (pp. 171-193) Norris, S., Maier, C.D. (Eds.). Berlin, DE: De Gruyter.

20. Djonov, E., Van Leeuwen, T. (2013). Between the Grid and Composition: Layout in PowerPoint's Design and Use. Semiotica 197, 1-34.

21. Dourish, P. (2006). Re-space-ing Place: "Place" and "Space" Ten Years On. In: Proc. CSCW '06. New York, NY: ACM Press, 299-308.

22. Eco, U. (1979). The Role of the Reader. Explorations in the semiotics of texts. Bloomington, IN: Indiana University Press.

23. Eco, U., Rorty, R., Culler, J., Brooke-Rose, C., Collini, S. (1992). Interpretation and Overinterpretation. Cambridge, UK: Cambridge University Press.

24. Gardiner, M.E. (2000) Critiques of Everyday Life. London \& New York: Routledge.

25. Garrote, R., Pettersson, T. (2011). The use of learning management systems: A Longitudinal Case Study. E-learning \& Education, 8.

26. Goldberg, D.A.M. (2004). The Scratch Is Hip-hop. Appropriating the Phonographic Medium. In: Appropriating Technology. Vernacular Science and Social Power. (pp. 107-144). Eglash, R., Croissant, J.L., Di Chiro, G., Fouché, R. (Eds.) Minneapolis, MN, University of Minnesota Press.

27. Halliday, M. A. K. (1978). Language as social semiotic: The social interpretation of language and meaning. Maryland, USA. University Park Press.

28. Hamid, S., Waycott, J., Kurnia, S., \& Chang, S. (2014). An empirical study of lecturers' appropriation of social technologies for higher education. Australasian Journal of Educational Technology. 30:3, 295-311.

29. Hamilton, E., Feenberg, A. (2012). Alternative Rationalisations and Ambivalent Futures: A Critical History of Online Education. In: Feenberg, A., Friesen, N. (Eds.) (Re)inventing the Internet. Critical Case Studies. (pp. 43-70). Rotterdam, NL: Sense Publishers.

30. Hatton, E.J. (1988). Teachers' Work as Bricolage: Implications for Teacher Education. British Journal of Sociology of Education . 9:3, 337-357.

31. Hemmi, A., Bayne, S., \& Land, R. (2009). The appropriation and repurposing of social technologies in higher education. Journal of Computer Assisted Learning . 25: $1,19-30$.

32. Hodge, R., \& Kress, G. (1988). Social semiotics. Cambridge, England: Polity Press. 
33. Holmberg, J. (2014). Studying the process of educational design - revisiting Schön and making a case for reflective design-based research on teachers' 'conversations with situations'. Technology, Pedagogy and Education. 23:3, 293-310.

34. Hutchinson, S.A. (2011). Boundaries and Bricolage. Examining the Role of Universities and Schools in Student Teacher Learning. European Journal of Teacher Education 34:2, 177-191.

35. Jewitt, C. (2006). Technology, Literacy and Learning. A Multimodal Approach. London, UK: Routledge.

36. Jewitt, C. 2010. An Introduction to Multimodality. In: Jewitt, C. (Ed.) The Routledge Handbook of Multimodal Analysis. (pp. 14-27). London, UK: Routledge.

37. Jewitt, C. (2013). Multimodal Methods for Researching Digital Technologies. In: Price, S., Jewitt, C., \& Brown, B. (Eds.) The SAGE Handbook of Digital Technology Research (pp. 250-265) London, UK: Sage.

38. Jewitt, C., Bezemer, J., O’Halloran, K. (2016). Introducing Multimodality. London, UK: Routledge.

39. Kali, Y., Goodyear, P., Markauskaite, L. (2011). Researching design practices and design cognition: contexts, experiences and pedagogical knowledge-in-pieces. Learning, Media and Technology, 36:2, 129-149.

40. Kjeldskov, J., Paay, J. (2010). Indexicality: understanding mobile human- computer interaction in context. ACM Transactions on Computer- Human Interaction 17:4, article 14.

41. KU Leuven (2012). Toledo. Information on the Digital Learning Environment Toledo. Available online: https://toledo.kuleuven.be/english/general/toledo_en Last accessed: Feb. 9, 2016.

42. Kress, G. (2003). Literacy in the new media age. London, UK: Routledge.

43. Kress, G. (2010). Multimodality. A Social Semiotic Approach to Contemporary Communication. New York, NY: Routledge.

44. Kress, G. 'Partnerships in Research': Multimodality and Ethnography. Qualitative Research 11 (2011) 239-260.

45. Kress, G., Selander, S. (2012). Multimodal Design, Learning and Cultures of Recognition. Internet and Higher Education 15, 265-268.

46. Lazar, J. \& Preece, J. (2003). Social Considerations in Online Communities: Usability, Sociability, and Success Factors. In: Van Oostendorp, H. (Ed.) Cognition in the Digital World. (pp. 127-151). London, UK: Lawrence Erlbaum.

47. Lazar, J., Feng, J., Hochheiser, H. (2010). Research Methods in Human-Computer Interaction. Chichester, UK: Wiley.

48. Lemke, J.L. (2002). Travels in Hypermodality. Visual Communication 1: 3, 299-325. 
49. Liu, K. (2000). Semiotics in Information Systems Engineering. Cambridge, UK: Cambridge University Press.

50. Medina, R., Suthers, D. (2012). Inscriptions Becoming Representations in Representational Practices. Journal of the Learning Sciences, 22:1, 33-69.

51. Mørch, A. (1997). Three Levels of End-User Tailoring: Customization, Integration, and Extension. In: Kyng, M., Mathiassen, L. (Eds.) Computers and Design in Context. (pp. 51-76) Cambridge, MA: The MIT Press.

52. O'Neill, S. (2008). Interactive Media: The Semiotics of Embodied Interaction. London, UK: Springer.

53. Overdijk, M., Van Diggelen, W., Andriessen, J., Kirschner, P. A. (2014). How to bring a technical artifact into use: A micro-developmental perspective. International Journal of Computer Supported Collaborative Learning , 9(3), 283-303.

54. Oudshoorn, N, Pinch, T. (2003). Introduction. In: Oudshoorn, N., Pinch, T. (Eds.) How Users Matter. The Co-Construction of Users and Technology. (pp. 1-25) Cambridge, MA: The MIT Press.

55. Pereira, R., Baranauskas, M.C.C., da Silva, S.R.P. (2013). Social Software and Educational Technology: Informal, Formal and Technical Values. Educational Technology \& Society 16:1, 4-14.

56. Pipek, V., Kahler, H. (2006). Supporting collaborative tailoring. In Lieberman, H., Paternò, F., Wulf, V. (Eds.) End user development (pp. 315-345). Dordrecht, NL: Springer Netherlands.

57. Prates, R.O., De Souza, C.S., Barbosa, S.D. (2000). Methods and Tools: A Method for Evaluating the Communicability of User Interfaces. Interactions 7:1, 31-38.

58. Price, S., Jewitt, C. (2013). A Multimodal Approach to Examining 'Embodiment' in Tangible Learning Environments. In: Proc. TEI 2013, 43-50.

59. Prieto, L.P., Asensio-Perez, J.I., Munoz-Cristobal, J.A., Dimitriadis, Y.A., JorrinAbellan, I.M., Gomez-Sanchez, E. (2013). Enabling Teachers to Deploy CSCL Designs across Distributed Learning Environments. IEEE Transactions on Learning Technologies, 6:4, 324-336.

60. Salovaara, A., Höök, K., Cheverst, K., Twidale, M., Chalmers, M., Sas, C. (2011). Appropriation and Creative Use: Linking User Studies and Design. In: CHI '11 EA. New York, NY: ACM Press, 37-40.

61. Salovaara, A., Öörni, A., Sokura, B. (2013). Heterogeneous Use for Multiple Purposes: A Point of Concern to IS Use Models' Validity. In: Proceedings of the Thirty Fourth International Conference on Information Systems (ICIS 2013) Milan, Italy.

62. Sharples, M., Adams, A., Ferguson, R., Gaved, M., McAndrew, P., Rienties, B., Weller, M., Whitelock, D. (2014). Innovating Pedagogy 2014. Exploring New Forms 
of Teaching, Learning and Assessment, to Guide Educators and Policy Makers. Milton Keynes, UK: The Open University.

63. Suthers, D.D. (2005). Technology affordances for intersubjective learning: a thematic agenda for CSCL. In: Proc. CSCL '05. International Society of the Learning Sciences, 662-671.

64. Van Leeuwen, T. (2005). Introducing Social Semiotics. New York, NY: Routledge.

65. Veletsianos, G., Kimmons, R., French, K.D. (2013). Instructor Experiences with a Social Networking Site in a Higher Education Setting: Expectations, Frustrations, Appropriation, and Compartmentalization. Education Tech Research Dev 61: 255278.

66. Wen, Y., Chen, W., Looi, C.-K., Xie, W. (2014). Appropriationg a Representational Tool for Collaborative Language Learning:a Comparative Study of Two Teachers' Enactment. Research and Practice in Technology Enhanced Learning, 9:1, 189-208.

67. Wen, Y., Looi, C.-K., Chen, W. (2015). Appropriation of a representational tool in a second-language classroom. International Journal of Computer-Supported Collaborative Learning 10, 77-108.

68. Won, M., Stiemerling, O., Wulf, V. (2006). Component-Based Approaches to Tailorable Systems. In: Lieberman, H., Paternò, F., Wulf, V. (Eds.) End User Development. (pp. 115-141). Dordrecht, NL: Springer.

69. Woolgar, S. (1991). Configuring the User: the Case of Usability Trials. In: Law, J. (Ed.) A Sociology of Monsters: Essays on Power, Technology and Domination. (pp. 57-99). London, New York: Routledge.

70. Xambò, A., Jewitt, C., Price, S. (2014). Towards an Integrated Methodological Framework for Understanding Embodiment in HCI. In: Proc. CHI 2014 EA. New York, NY: ACM Press, 1411-1416.

71. Zhao, S., Djonov, E., Van Leeuwen, T. (2014). Semiotic Technology and Practice: A Multimodal Social Semiotic Approach to PowerPoint. Text\&Talk 34:3, 349-375. 


\section{APPENDIX A: TOLEDO DIARY}

\section{General Information}

Name

Year of birth

Faculty / department

Do you consider yourself an experienced user of technology and computers? Rate yourself on a scale from zero (very unexperienced) to ten (very experienced).

Which devices do you use while teaching, or preparing for it?

- Desktop PC

- Laptop

- Smartphone

- Tablet

- E-reader

- Other:

Do you consider yourself an experienced Toledo user? Rate yourself on a scale from zero (very unexperienced) to ten (very experienced).

Are you satisfied using Toledo as a learning environment for the courses you teach? Why (not)?

\section{General Questions on Toledo}

Do you consider Toledo to be a user-friendly platform? Why (not)?

Do you use the Toledo smartphone app, and/or the mobile website? When?

Do you use other tools or platforms to manage courses and course material, and to make the material available for students? Which ones?

\section{Specific Use Sessions}

Day:

Time: $x x: x x$ until $x x: x x$

Activity: I used Toledo to:

- Manage courses,

- Making information available, or adjusting information:

○ Making course materials available, or adjusting them (texts, presentations,...),

- Writing blog posts, or contributing / changing articles on a wiki,

- Creating assignments for students,

o Other:

- Communicate:

- Communcating with individual students (via e-mail,...),

- Communicating with groups of students (practical course information),

- Mediating communication among students,

○ Other: 
- Evaluate:

- Creating tests

- Consulting or making available information on students (test/assignment results)

- Providing feedback about tests

o Other:

- Other:

Location: I used Toledo:

- During a lecture,

- At home,

- At the office,

- Other:

- What was your goal? Did you achieve that goal?

- Did you experience any problems with Toledo during the session? Which ones?

- Are you satifisfied about this session of Toledo use? Rate this on a scale from zero (unsatisfied) to ten (very satisfied).

- What would have made your use of Toledo easier?

- Did you use any other tools during this session? Which ones? Why? 


\section{APPENDIX B: INTERVIEW GUIDE}

\section{General Interview Questions}

- How long have you been using Toledo?

- How many courses do you teach? Which subjects do you teach? How big are the groups of students? Do you have personal contact with the students?

- Are you also responsible for other activities (such as research)?

- Have you ever participated in workshops or other activities about Toledo?

- Is the use of Toledo compulsory in your department, or is it optional?

- Do you use other (technological or non-technological) resources in your teaching? Which ones?

- Which functionalities in Toledo do you use?

- How do you feel about Toledo? Is the platform easy to use?

\section{Specific Diary Questions and Evolution of Toledo Use}

The specific diary questions provided more details about the entries in the respondents' diaries. Common clarifications in this part of the interview included:

- questions about the nature of their activities / tool use. For instance, when most sessions included a specific tool, respondents were asked whether this frequent use of the specific tool is typical for their Toledo use,

- questions about problems that were encountered during the sessions,

- questions about specific appropriations that were mentioned in the diary

- questions about the respondents' use of other tools outside Toledo.

In order to minimize a potential bias based on a limited two-week study, the respondents were asked to draw a graph of their Toledo use. This provided more information about both the frequency of use, and the nature of the respondents' tasks as they evolves over the course of an academic year (see Figure B.1).

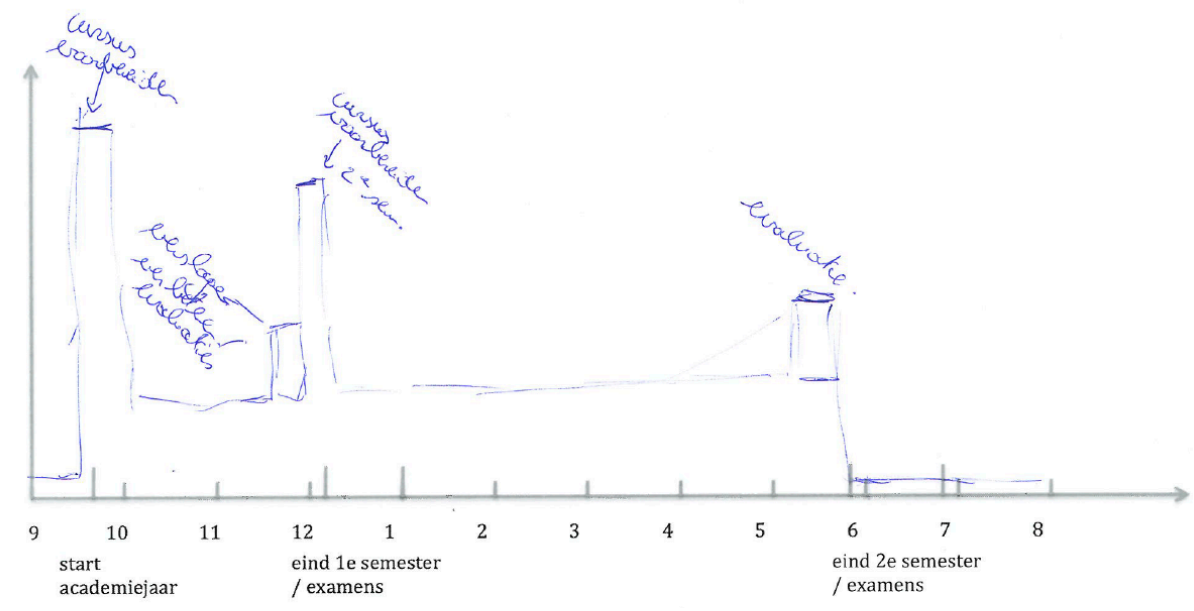

Figure B.1: Graph of Toledo use throughout the academic year. 